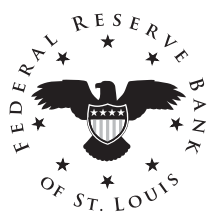

\title{
U.S. Currency at Home and Abroad
}

$\mathrm{D}$ espite the increasing use of electronic payments and credit cards, currency remains the most familiar medium for face-to-face transactions in the U.S. economy. In addition, U.S. currency, more than any other of the world's currencies, is widely held as a store of value and used as a medium of exchange outside its home country. The chart shows the currency component of M1 and the Federal Reserve Board staff's estimates of U.S. currency held by the rest of the world. In 2005, approximately 50 percent of all U.S. currency in circulation, or about $\$ 350$ billion, was held outside the United States.

U.S. currency is an attractive asset to residents of nations with political or economic uncertainty. Much of the recent growth in demand for U.S. currency has been in countries of the former Soviet Union and Latin America. Indeed, anecdotal press reports tell of Moscow taxi drivers insisting to be paid in U.S. dollars rather than rubles. Other stories tell of merchants in the most remote areas of China accepting - and giving change in-U.S. banknotes. The extensive, widespread use of U.S. currency benefits American taxpayers because, unlike Treasury bonds, the currency is a liability of the Treasury on which no interest is paid. ${ }^{1}$ The use of the banknotes also is a social and economic benefit to the residents of foreign countries who might otherwise lack a currency that is stable in value and widely accepted in transactions. This same popularity also is a curse, encouraging counterfeiting of U.S. banknotes. Despite the temptation and potential profit from counterfeiting, the Treasury and Federal Reserve estimate that the frequency of counterfeiting is low, approximately 1 note in 10,000 both in the United States and abroad. At Federal Reserve cash offices, during 2005, $\$ 100$ denominations had the highest frequency of counterfeit notes, at 44.1 notes per million processed, followed by $\$ 10$ denominations, at 7.8 notes per million. Overall, 6.4 counterfeit notes were detected per million notes processed. ${ }^{2}$

Technological innovations in color copying, scanning, and printing have intensified the race between increasingly sophisticated banknote counterfeiters and government banknote designers. Perhaps the most difficult-toduplicate counterfeit deterrence feature of U.S. banknotes is its unique yellow-green paper. Combined with intaglioprinted images and numerals, U.S. currency has a unique "feel," which surveys have reported is the most common method of counterfeit detection by the public and bank employees. Other features include magnetic ink, large detailed presidential portraits, color-shifting ink in the front lower-right corner of notes (the color of which differs by denomination), watermarks, security threads that glow different colors under ultraviolet light, microprinting, subtle shades of color overprinted on the front and reverse, and embedded machinereadable features.

As the design of U.S. currency has been revised through time to deter counterfeiting, an underlying principle of the Bureau of Engraving and Printing has been to retain the distinctive "American look" of U.S. banknotes: All denominations are physically the same size and use the same primary ink color. For at least 30 years, however, advocates for the visually impaired have asked for changes to make U.S. currency more accessible, including note size that varies by denomination. Any such redesign of U.S. currency would need to be studied carefully, to avoid reducing the international recognition and acceptance of U.S. currency, and be accompanied by an effective public education program to ensure its continued acceptance at home and abroad.

\section{— Richard G. Anderson and Marcela M. Williams}

${ }^{1}$ Technically, currency is a liability of the Federal Reserve Banks. But, because the Banks hold Treasury securities as specific collateral against currency and return to the Treasury nearly all the interest they receive on these bonds, for practical purposes currency may be regarded as a liability of the Treasury.

2 United States Treasury Department, The Use and Counterfeiting of United States Currency Abroad, Part 3, September 2006.

Views expressed do not necessarily reflect official positions of the Federal Reserve System.

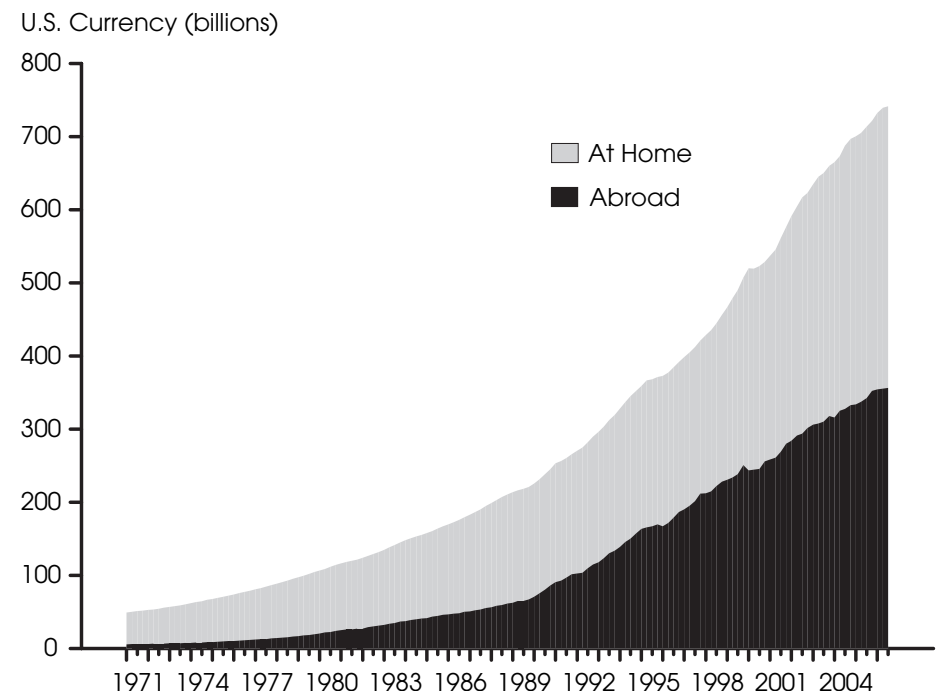

